\title{
Herbal medicine AnoSpray suppresses proinflammatory cytokines COX-2 and RANTES in the management of hemorrhoids, acute anal fissures and perineal wounds
}

\author{
ASHWIN PORWAL ${ }^{1}$, GOPAL C. KUNDU ${ }^{2,3}$, GAJANAN BHAGWAT ${ }^{4}$ and RAMESH BUTTI ${ }^{2,4}$ \\ ${ }^{1}$ Healing Hands Clinic, Pune, Maharashtra 411001; ${ }^{2}$ Laboratory of Tumor Biology, \\ Angiogenesis and Nanomedicine Research, National Centre for Cell Science, Pune, Maharashtra 411007; \\ ${ }^{3}$ School of Biotechnology and Kalinga Institute of Medical Sciences, KIIT Deemed to be University, \\ Institute of Eminence, Bhubaneswar, Odisha 751024; \\ ${ }^{4}$ R\&D Center, Healing Hands \& Herbs Pvt. Ltd., Pune, Maharashtra 411002, India
}

Received June 1, 2021; Accepted September 30, 2021

DOI: $10.3892 / \mathrm{etm} .2021 .11009$

\begin{abstract}
Hemorrhoids, anal fistula and fissure are common anorectal complications. Anorectal diseases are associated with severe pain, inflammation, swelling, itching and bleeding. These diseases may be managed with different medical treatments or surgical procedures, depending on their severity. Surgical procedures, however, are highly invasive and are associated with higher costs and the possibility of recurrence. In addition, surgical removal of fistula-in-ano leads to the formation of perineal wounds. Therefore, developing therapeutic interventions that are effective in alleviating inflammation and pain are desirable for the effective management of anorectal diseases. Herbal compounds have previously been indicated to suppress inflammation and pain in different pathological conditions. The aim of the present study was to examine the effects elicited by a polyherbal formulation, AnoSpray ${ }^{\circledR}$, on the migration of inflammatory cells and on the expression of inflammatory cytokines in anorectal diseases. The effect of AnoSpray on cell viability and migration was studied using MTT and wound-migration assays, respectively. Furthermore, the effects of AnoSpray on the expression of the inflammatory cytokines regulated upon activation, normal $\mathrm{T}$ cell expressed and presumably secreted (RANTES) and VEGF, as well as on cyclooxygenase-2 (COX)-2, were investigated using western blot analysis. The expression of RANTES and COX-2 in human hemorrhoid specimens was also analyzed to corroborate the in vitro findings. The results obtained revealed that AnoSpray did not exhibit any cytotoxic effects; however,
\end{abstract}

Correspondence to: Dr Ashwin Porwal, Healing Hands Clinic, 4th Floor, Millennium Star Extension, Building-B, Dhole Patil Road, Pune, Maharashtra 411001, India

E-mail: drashwinporwal@healinghandsclinic.co.in

Key words: AnoSpray, pilospray, cytotoxicity, inflammation, cytokine, RANTES, COX-2, anorectal disorders it did lead to a significant suppression in the migration of RAW 264.7 and BJ cells. Furthermore, the results suggested that AnoSpray suppressed the expression of the inflammatory cytokines RANTES and VEGF, and also the expression of COX-2. In addition, RANTES and COX-2 were significantly downregulated in the clinical specimens of AnoSpray-treated hemorrhoids compared with the controls. Taken together, the results of the present study suggested that AnoSpray may be a potential therapeutic agent in the treatment of bleeding hemorrhoids, anal fissures and perineal wounds.

\section{Introduction}

Anorectal conditions are among the most common problems encountered in clinical practice. Anorectal diseases such as hemorrhoids, anal fissure, anorectal abscesses, anal fistula, proctalgia fugax and pruritus ani exhibit overlapping symptoms, which may be distinguished based on consideration of the detailed history of the patient and anorectal examination (1).

Hemorrhoids represent the most common anorectal disorder and arise due to engorgement of vascular cushions in the lower rectum/anus $(2,3)$. Hemorrhoids may be located inside the anal canal (termed 'internal hemorrhoids') or they present at the anal opening ('external hemorrhoids'). If external hemorrhoids become filled with blood clots, this leads to the formation of thrombosed hemorrhoids. Hemorrhoids are traditionally classified into grades I-IV, where grade I hemorrhoids are purely internal, grade II hemorrhoids prolapse on staining but reduce spontaneously, grade III hemorrhoids are characterized by their prolapsing requiring manual reduction and grade IV hemorrhoids are prolapsed and non-reducible (3). According to current estimates, $75 \%$ of the world population will suffer from bleeding hemorrhoids at a certain point in their lives (4), indicating that hemorrhoids are a major socioeconomic and medical problem. Hemorrhoids occur commonly in both genders, with a peak incidence arising between the fourth and sixth decades of life $(5,6)$. Even though the precise underlying cause of hemorrhoids has not been fully elucidated, risk 
factors for hemorrhoids include straining during defecation as a consequence of constipation, obesity, pregnancy, old age, chronic diarrhea, anal intercourse, cirrhosis with ascites, pelvic floor dysfunction and having a low-fiber diet $(7,8)$. Although $40-55 \%$ of cases exhibit no symptoms (9), those patients who are symptomatic frequently exhibit pain, bleeding, prolapse, soiling, grape-like tissue prolapse, itching or a combination of these symptoms (3). Various physiological changes, including abnormal distension of veins, destruction of collagen fibers and fibroelastic tissues, and damage of the anal subepithelial muscle occur during hemorrhoidal progression (10). Inflammatory reactions in the affected area have been indicated to be associated with mucosal ulceration, ischemia and thrombosis (11). Several enzymes, including matrix metalloproteinases, thrombin and plasmin, as well as an array of signaling factors, are involved in the degradation of the supporting tissues in the anal cushions, which consist of collagen, fibronectin and elastin fibers. These events gradually lead to the promotion of angiogenic and proliferative activity mediated by transforming growth factor $\beta$ as part of the healing process $(12,13)$. Various surgical options, including stapled hemorrhoidopexy and hemorrhoidectomy, are available as treatment procedures; however, these methods are highly invasive and associated with higher costs $(2,14)$. Furthermore, these surgical options are largely unsuccessful, as recurrence, pain and bleeding are major concerns after the procedure $(15,16)$.

An anal fissure is a tear of the anoderm in the anal canal that is caused by mechanical trauma, sphincter spasm or ischemia (17). Anal fissures exhibit overlapping symptoms with hemorrhoids (18) and are always associated with twinges of pain (19). Chronic fissures typically require medical treatment or surgical therapy. Surgical procedures have superior healing rates compared with local medical therapies, although they may result in persistent incontinence (20).

An anal fistula is an epithelialized tract or a connection between the anal canal and the perianal skin. Classical anal fistulas result from a perineal infection and abscess formation (21). Fistulas are also associated with inflammatory bowel disease, radiation, malignancy, chronic diarrhea or pre-existing incontinence (22). Perineal wounds usually result from low pelvic tumors, ablation of the tumor, trauma, perineal infections and electrical or thermal burns (23). Furthermore, various surgical procedures for fistula-in-ano may also lead to poorly healing perineal wounds and impaired continence (24). Patient- and surgery-associated factors, including obesity, being overweight, hypoalbuminemia, extralevator abdominal resection, intraoperative perforation and supine position during the second phase of labor, are associated with delayed perineal wound healing (25-29). Delayed perineal wounds are associated with morbidity, prolonged hospital stays, higher costs, home nursing care needs and lower rates of survival $(23,30)$. Therefore, developing minimally invasive therapeutic interventions that help to alleviate inflammation and pain in anal fissures, bleeding hemorrhoids and perineal wounds would be beneficial for patients.

Herbal products are an important source of medicinal compounds (31). Traditional medicinal compounds are known to suppress pain and inflammation under different pathological conditions (32). Herbal medicines suppress inflammation by downregulating the recruitment of inflammatory cells, as well as through suppressing inflammatory cytokine expression (33). Cytokines such as regulated upon activation, normal $\mathrm{T}$ cell expressed and presumably secreted (RANTES), IL-1 $\beta$ and VEGF are proinflammatory cytokines that contribute to inflammation and pain in different pathological settings $(33,34)$. Cyclooxygenase-2 (COX-2) is an enzyme that is involved in the formation of prostaglandins, which are crucially involved in promoting inflammation (35). The expression of COX-2 is regulated by growth factors and different inflammatory cytokines, including IL-1 $\beta$, IL-6 and tumor necrosis factor- $\alpha$ (TNF- $\alpha$ ), and therefore, its expression is upregulated during inflammation (35). The use of natural products for the treatment of these ailments is indeed cost-effective and minimally invasive $(32,36)$. A previous study by our group assessed the safety and efficacy of a polyherbal formulation, AnoSpray ${ }^{\circledR}$ for the treatment of perineal wounds using a single-center, open-label, randomized parallel-group trial. The results indicated that the use of AnoSpray provided a marked improvement in treating perineal wounds as compared to betadine solution (37). However, at present, the underlying mechanism through which AnoSpray exerts its effects on anorectal diseases has remained elusive. The aim of the present study was to investigate the cytotoxicity and molecular action of AnoSpray in anorectal diseases. The data obtained on fibroblasts and macrophages revealed that it was safe to use. Furthermore, it was demonstrated that AnoSpray suppressed the migration of these cells and ameliorated the expression of inflammatory factors in both an in vitro model and in clinical specimens of anorectal disease. Collectively, the results confirmed the benefit of AnoSpray treatment in the clinical management of hemorrhoids, anal fissures and perineal wounds.

\section{Materials and methods}

Cell culture. The mouse monocyte/macrophage-like cell line RAW 264.7 and human foreskin fibroblasts (BJ cell line) were obtained from the American Type Culture Collection. The RAW 264.7 and BJ cells were cultured in RPMI-1640 (Gibco; Thermo Fisher Scientific, Inc.) and Minimum Essential Medium (Eagle) $[\operatorname{MEM}(\mathrm{E})]$ (HiMedia Laboratories, LLC) media, respectively. The culture media were supplemented with $10 \%$ fetal bovine serum (Gibco; Thermo Fisher Scientific, Inc.) and 100 units of penicillin $/ 100 \mu \mathrm{g} / \mathrm{ml}$ streptomycin (HiMedia Laboratories, LLC), and the cells were grown in a humidified incubator in an atmosphere with $5 \% \mathrm{CO}_{2}$ at $37^{\circ} \mathrm{C}$.

Drug preparation. The formulation of AnoSpray/PiloSpray ${ }^{\circledR}$ (Healing Hands \& Herbs Pvt. Ltd.; https://healinghandsandherbs.in/) was mentioned in a previously published study (37). Similar to AnoSpray/PiloSpray (see https://pilospray. com/AnoSpray-advanced-piles-spray/) is an over-the-counter brand name of the formulation; essentially, AnoSpray/PiloSpray is an Ayurvedic polyherbal formulation in the form of a spray. AnoSpray/PiloSpray consists of lodhara (Symplocos racemosa), daruharidra (Berberis aristata), mocharas (Bombax ceiba), kapur (Cinnamomum camphora), pudinah (Mentha piperita), til oil (Sesamum indicum) and kokam oil (Garcinia indica) in aerosol form. 'AnoSpray' or 'PiloSpray' is used as the brand 
name to refer to the polyherbal spray formulation in the present study.

Cell viability assay. Cell viability was assessed using an MTT assay, following the instructions provided in a previously described protocol (38). In brief, RAW 264.7 and BJ cells (density, $2 \times 10^{4}$ cells/well) were seeded into 96-well microplates (with flat bottoms) and treated with AnoSpray at concentrations of $0-7.5 \mu \mathrm{l} / \mathrm{ml}$ for $24 \mathrm{~h}$. MTT $(0.5 \mathrm{mg} / \mathrm{ml})$ solution was added to each well and the plates were incubated for $4 \mathrm{~h}$ at $37^{\circ} \mathrm{C}$. Subsequently, the MTT solution was carefully aspirated and isopropanol was added to dissolve the formazan crystals. The optical density of the formazan solution was subsequently recorded at $570 \mathrm{~nm}$ using an automated microplate reader (EPOCH2; Bio Tek Instruments, Inc.). All experiments were performed in triplicate.

Wound-closure assay. Cell migration was studied using a conventional wound-closure/migration assay, as per the standard protocol described previously (39). In brief, RAW 264.7 and BJ cells (density, 2x10 cells) were seeded into 12-well plates and allowed to attain a confluent monolayer. Upon reaching $100 \%$ confluence, the monolayers were scratched using a sterile $200-\mu 1$ pipette tip and the old medium was removed to remove detached cells. Fresh RPMI-1640 complete medium $(1 \mathrm{ml})$ was added to the cells prior to the treatments Cells were subsequently incubated at $37^{\circ} \mathrm{C}$ with AnoSpray at concentrations of $0-7.5 \mu \mathrm{l} / \mathrm{ml}$. Photographs were acquired at 0 and 12/16 h using a using a phase-contrast microscope (magnification, x100; Nikon Corporation). The area of wound closure was measured using Image-Pro Plus 6.0 software (National Institutes of Health).

Western blot analysis. Western blot analysis was performed as per a standard procedure described previously (40). Specifically, RAW 264.7 and BJ cells $\left(5 \times 10^{5}\right.$ cells) were seeded in $60-\mathrm{mm}$ dishes. On the next day, the cells were treated with different concentrations of AnoSpray $(0-7.5 \mu \mathrm{l} / \mathrm{ml})$. Cells were harvested by centrifuging the cells at $1,000 \mathrm{x} g$ at room temperature for $10 \mathrm{~min}$ and lysed using RIPA buffer. The protein concentration was estimated in cell lysates using Bradford reagent and equal amounts of total protein (30 $\mu \mathrm{g}$ /lane) were resolved by 10 or $12.5 \%$ SDS-PAGE. The separated proteins were transferred to a polyvinylidene difluoride membrane (Bio-Rad Laboratories, Inc.) and processed for further analysis Non-nspecific binding sites were blocked by incubating membranes in 5\% skimmed milk at room temperature for $1 \mathrm{~h}$. The membranes were subsequently incubated with primary antibodies (obtained from Santa Cruz Biotechnology, Inc.) against COX-2 (cat. no. sc-1746; 1:1,000), RANTES (cat. no. sc-1410; 1:1,000), VEGF (cat. no. sc-7269, 1:1,000 dilution) and $\beta$-actin (Santa Cruz Biotechnology, Inc., cat. no. sc-1615, 1:2,000) overnight at $4^{\circ} \mathrm{C}$, followed by incubation with anti-goat HRP (Santa Cruz Biotechnology, Inc.; cat. no. sc-2020; 1:2,000) or anti-mouse HRP antibodies (Santa Cruz Biotechnology, Inc.; cat. no. sc-2005; 1:2,000) for $1 \mathrm{~h}$ at room temperature. All blots were visualized using the Clarity Western ECL reagent (Bio-Rad Laboratories, Inc.). Densitometry analysis was performed using ImageJ2 software (National Institutes of Health) and fold-changes were calculated following normalization to $\beta$-actin.

Analysis of clinical specimens. The present study was approved by the Institutional Ethics Committee of Healing Hands Clinic (Pune, India). Patients with hemorrhoids were treated thrice a day for at least 15 days with AnoSpray. Human hemorrhoid specimens derived from the surgical removal of hemorrhoids $(n=10)$ were collected between March 2020 and February 2021 with the help of a histopathologist from Healing Hands Clinic (Pune, India) and written informed consent was obtained from each of the patients. Paraffin-embedded tissue blocks were prepared and $5-\mu \mathrm{m}$ sections were cut and deposited on poly-L-lysine-coated slides. Immunohistochemical analysis was performed using the SuperSensitive ${ }^{\mathrm{TM}}$ Polymer-HRP IHC Detection System (BioGenex Laboratories), as per the manufacturer's protocol. In brief, the sections were deparaffinized in xylene and rehydrated in an alcohol gradient. Subsequently, the sections were subjected to antigen retrieval in citrate buffer at $90^{\circ} \mathrm{C}$ for $15 \mathrm{~min}$. Sections were covered with peroxide for $10 \mathrm{~min}$ to block endogenous peroxidase activity, followed by power block (provided as part of the SuperSensitive $\mathrm{T}^{\mathrm{TM}}$ Polymer-HRP IHC Detection System) to block non-specific binding sites. Sections were then incubated with primary antibodies against COX-2 (1:100) and RANTES (1:100) overnight at $4^{\circ} \mathrm{C}$, and subsequently with specific secondary antibodies for $1 \mathrm{~h}$ at room temperature. Liquid DAB chromogen was added at room temperature for $10 \mathrm{~min}$ and images of the tissue sections were captured using a Nikon Eclipse microscope (magnification, x200; Nikon Corporation).

Statistical analysis. Each experiment was performed in triplicate and the results were expressed as the mean \pm SEM. Statistical analysis was performed using GraphPad Prism 5.0 software (GraphPad Software, Inc.). An unpaired Student's t-test was utilized to assess statistical difference between two groups, whereas the Kruskal-Wallis test was used to measure statistical significance in the case of multiple doses of drug treatments with the Dunn's post-hoc test. $\mathrm{P}<0.05$ was considered to indicate a statistically significant difference.

\section{Results}

Effect of AnoSpray on the viability of fibroblasts. A previous study by our group (37) reported on the safety of AnoSpray treatment in humans for the management of perineal wounds. The present study aimed to investigate the in vitro cytotoxic effects of AnoSpray on macrophage and fibroblast cell lines to assess its safety in therapeutic use. RAW 264.7 (macrophage) and BJ (fibroblast) cells were used for assessing the effect of AnoSpray on cell viability. The RAW 264.7 and BJ cell lines in culture were treated with AnoSpray in a concentration-dependent manner $(0-7.5 \mu \mathrm{l} / \mathrm{ml})$ to study its effect on cell viability using an MTT assay. The percentage cell viability was measured and the results obtained were statistically analyzed using the Kruskal-Wallis test. The results indicated that AnoSpray did not have any significant effects on the viability of the mouse macrophage cell line RAW264.7 (Fig. 1A). Subsequently, the effect of AnoSpray on the viability of the human normal fibroblast cell line BJ was 

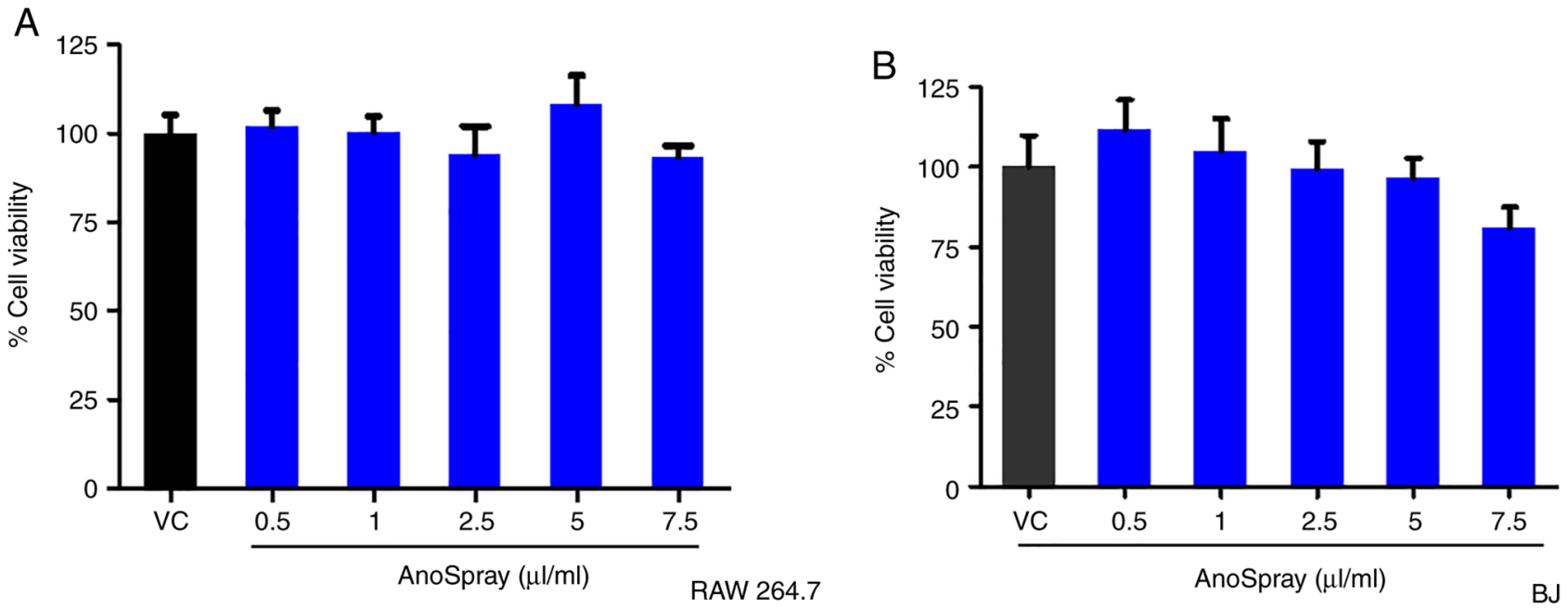

Figure 1. Effect of AnoSpray ${ }^{\circledast}$ on cell viability. (A) RAW 264.7 cells were incubated with VC/AnoSpray ${ }^{\circledast}$ at specified doses $(0-7.5 \mu 1 / \mathrm{ml})$ for $24 \mathrm{~h}$ and an MTT assay was performed to examine cell viability. (B) BJ cells were treated with VC/AnoSpray ${ }^{\circledR}$ at specified doses $(0-7.5 \mu \mathrm{g} / \mathrm{ml})$ and an MTT assay was performed to study the effect of AnoSpray ${ }^{\circledR}$ on cell viability. Bar graphs represent the effect of AnoSpray ${ }^{\circledR}$ on the viability of the above cells. Values are expressed as the mean \pm standard error of the mean $(n=3)$. A Kruskal-Wallis test was performed to determine statistically significant differences between different treatment group means vs. VC. VC, vehicle control.

also studied using an MTT assay. Similar to the results for the RAW 264.7 cell line, AnoSpray did not appear to significantly affect the viability of the BJ cells (Fig. 1B). Based on these findings, it was possible to infer that AnoSpray did not affect the viability of macrophages and fibroblasts in vitro, thereby demonstrating its safety for therapeutic applications.

Effect of AnoSpray on the migration of fibroblasts. Wound healing is a complex and dynamic process that is involved in the recovery of the structure and functions of injured tissues (32). Prolonged inflammation at the site of injury delays the wound-healing process, inducing pathological pain $(41,42)$. In anorectal diseases, inflammation has a fundamental role in the aetiology of hemorrhoids (10), fissures (43) and perineal wounds (44). Macrophages and fibroblasts are recruited at the site of wounds and are involved in the synthesis of extracellular matrix and secretion of proinflammatory cytokines $(41,45)$. Therefore, the effects of AnoSpray treatment on the migration of macrophages and fibroblasts were studied using a conventional wound closure assay. Monolayers of macrophages and fibroblasts in culture were wounded and subsequently treated with different concentrations of AnoSpray (0-7.5 $\mu \mathrm{l} / \mathrm{ml})$. The percentage migration values were then analyzed and significant differences between the groups were assessed using Student's t-test. The results revealed that the migration of RAW 264.7 cells was significantly reduced upon AnoSpray treatment in a concentration-dependent manner (Fig. 2A and B). Similar results were obtained with the BJ cells. AnoSpray treatment led to a decrease in the migration rates of these cells (Fig. 2C and D), suggesting that AnoSpray has a significant role in impeding the migration of fibroblasts and macrophages.

Effect of AnoSpray on the expression of inflammatory cytokines. Inflammatory cytokines are highly expressed in anorectal diseases and are involved in pain, inflammation and itching (44,46-48). Inflammatory mediators, including COX-2, RANTES, VEGF, TNF- $\alpha$ and IL1- $\beta$, are known to be highly expressed under different pathological conditions $(49,50)$. Since fibroblasts and macrophages have been reported to express proinflammatory mediators $(51,52)$, macrophages and fibroblasts were used in the present study to examine changes in the expression levels of these cytokines upon treatment with AnoSpray (Fig. 3). Even though the endogenous expression levels of RANTES and VEGF are low in RAW 264.7 cells, the protein expression levels of these cytokines in RAW 264.7 cells were significantly suppressed upon treatment with AnoSpray compared with those in the control cells, as determined using western blot analysis (Fig. 3A). In addition, the endogenous expression of COX-2 was reduced in RAW 264.7 cells upon incubation with AnoSpray (Fig. 3A). The western blots for RANTES, VEGF and COX-2 were subsequently quantified and statistically analyzed using one-way ANOVA. The results revealed that the expression of these cytokines and COX-2 were significantly downregulated in RAW 264.7 cells (Fig. 3B). The expression levels of RANTES and VEGF were also examined in BJ fibroblasts using western blot analysis. The results revealed that the expression levels of these markers were markedly reduced in the AnoSpray-treated cells (Fig. 3C). Densitometric analysis was also performed for the western blot data for RANTES and VEGF, followed by statistical analysis using one-way ANOVA. This analysis revealed that the expression levels of these cytokines were significantly decreased in BJ cells (Fig. 3D). Collectively, these results indicated that AnoSpray treatment downregulated the expression of the two proinflammatory cytokines and COX-2 in macrophages and fibroblasts.

AnoSpray suppresses the expression of COX-2 and RANTES. To further corroborate the in vitro results in clinical specimens, the expression levels of the proinflammatory cytokines RANTES and COX-2 were examined in hemorrhoidal tissues, where they are known to induce pathological pain. Hemorrhoidal patients were treated with AnoSpray for at least 15 days. The expression levels of RANTES as well as COX-2 
A
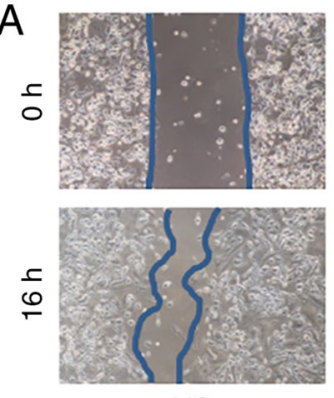

VC

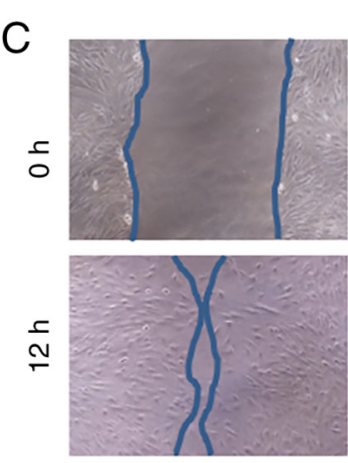

VC
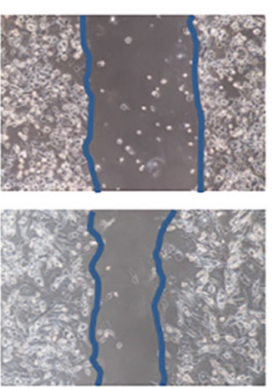

5

AnoSpray $(\mu \mathrm{l} / \mathrm{ml})$

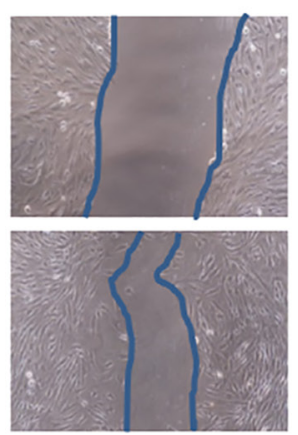

5
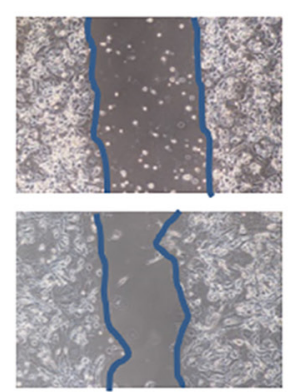

7.5

RAW 264.7
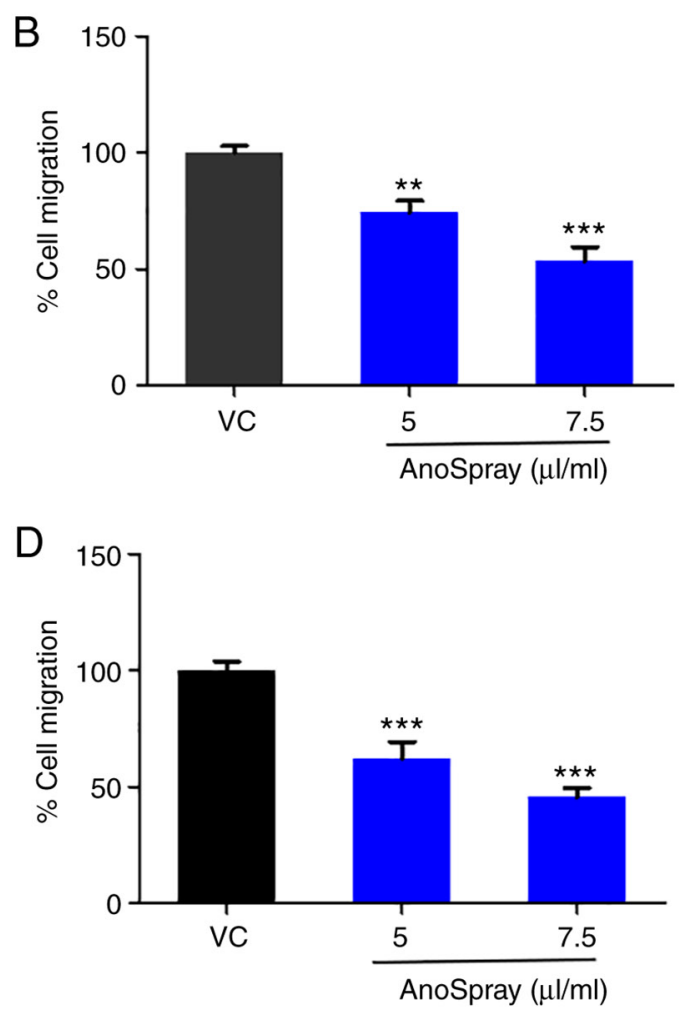

AnoSpray $(\mu \mathrm{l} / \mathrm{ml})$

BJ

Figure 2. Effect of AnoSpray ${ }^{\circledR}$ on cell migration. RAW 264.7 and BJ cells were treated with AnoSpray ${ }^{\circledR}(0-7.5 \mu 1 / \mathrm{ml})$ and a wound migration assay was performed to study the effect of AnoSpray ${ }^{\circledR}$ on cell migration. Images were captured at 0 and $12 / 16$ h. (A) Images representing the effect of AnoSpray ${ }^{\circledR}$ on the migration of RAW 264.7 cells. (B) Bar graph depicting quantitative wound migration assay results. (C) Images indicating the effect of AnoSpray ${ }^{\circledR}$ on the migration of BJ cells (magnification, x100). (D) Bar graph presenting quantitative wound migration assay results. Values are expressed as the mean \pm standard error of the mean $(n=3) .{ }^{* *} \mathrm{P}<0.01,{ }^{* * *} \mathrm{P}<0.001$. VC, vehicle control.

were examined in both control $(n=5)$ and AnoSpray-treated $(n=5)$ human hemorrhoid specimens using immunohistochemical analysis. The results of these experiments indicated that RANTES and COX-2 were highly expressed in hemorrhoidal tissues (Fig. 4A and B). Furthermore, it was noted that the expression of RANTES and COX-2 was decreased in AnoSpray-treated $(n=5)$ clinical hemorrhoid specimens (Fig. 4C and D). These results clearly indicated that AnoSpray treatment suppressed the expression of proinflammatory cytokines in hemorrhoids.

\section{Discussion}

Hemorrhoids, anal fissures and fistulas are common benign anorectal diseases (22). These pathological ailments significantly impact the lifestyles of patients afflicted with these diseases, and primary or secondary medical care is usually required, depending on the severity of the disease. Grade I and, in certain cases, grade II hemorrhoids may be treated with dietary and lifestyle modifications or medical treatment options such as sclerotherapy. However, high-grade hemorrhoids require highly invasive surgical options $(10,53)$, which are usually associated with postoperative pain, bleeding and fecal urgency $(15,16,54)$. Furthermore, owing to the high recurrence rates that ensue after performing these procedures, these surgical methods only have partial success $(15,16)$. Anal fissures have several symptoms that are similar to those of hemorrhoids, including severe pain. Anal fissures may be divided into acute and chronic categories. Acute fissures may be effectively treated with conservative therapies (55), whereas chronic fissures typically require medical management or surgical therapy (20). Invasive interventions have greater healing rates compared with the administration of local medical therapies; however, they are associated with a risk of persistent incontinence (20). Anal fistulas may be treated with operative procedures; however, recurrence and the formation of perineal wounds limit the success of operational procedures (24). In addition, the surgical management of anorectal conditions is both invasive and associated with higher costs $(2,14)$. It was observed that delayed wound healing due to inflammation is responsible for disease-associated morbidities, including pain. Therefore, developinging novel minimally invasive and economical therapeutic interventions that exhibit inflammation and pain-suppressive activities may be beneficial for the betterment of the lives of patients with anorectal diseases.

Natural products are an important source of bioactive compounds and have been used since ancient times for the treatment of various diseases (56). Natural products with medicinal properties are also able to facilitate the wound-healing process (32). Several studies on the wound-healing activities of natural products have been performed. Herbal products with anti-inflammatory, antioxidant, antibacterial and pro-collagen synthesis properties have been indicated to elicit positive effects on wound healing. The medicinal properties of herbal products may be attributable to the presence of various bioactive phytochemical constituents, including alkaloids, oils, flavonoids, 

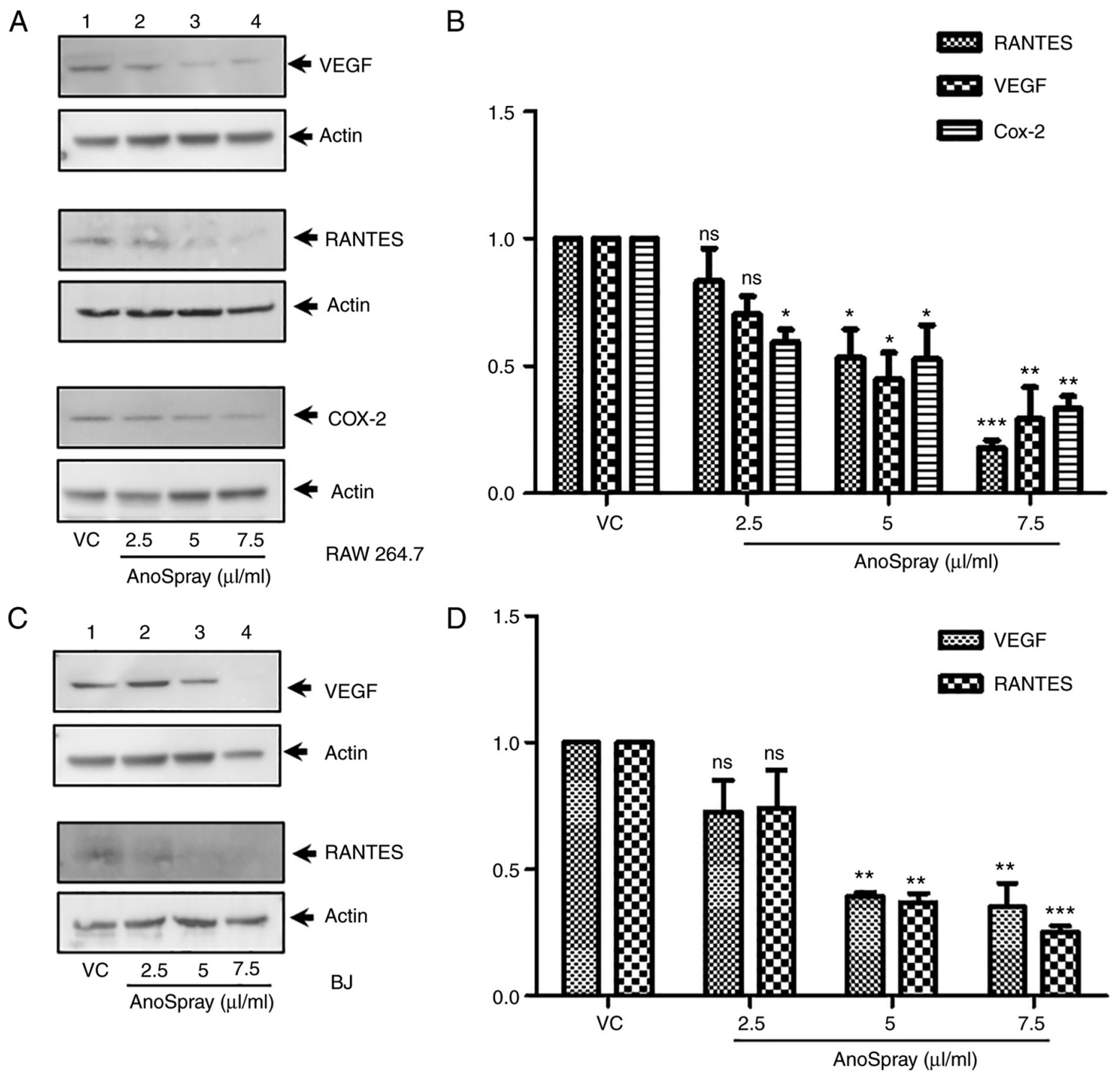

Figure 3. Effect of AnoSpray ${ }^{\circledR}$ on the expression of proangiogenic and proinflammatory factors. RAW 264.7 and BJ cells were stimulated with VC/AnoSpray ${ }^{\circledR}$ $(0-7.5 \mu \mathrm{g} / \mathrm{ml})$ and immunoblotting was performed to determine the expression of RANTES, VEGF and COX-2. (A) RAW 264.7 cells were treated with AnoSpray ${ }^{\boxplus}$ and the expression of VEGF, RANTES and COX-2 was determined by western blot. (B) Densitometry analysis was performed to quantify western blot results for VEGF, RANTES and COX-2 expression, presented in a bar graph. (C) BJ cells were treated with AnoSpray ${ }^{\circledR}$ and the expression of VEGF and RANTES was analyzed by western blot. (D) Densitometry analysis was performed to quantify western blot data for the expression of VEGF and RANTES, presented in a bar graph. Values are expressed as the mean \pm standard error of the mean $(n=3)$. Statistical significance was determined by one-way ANOVA. ${ }^{*} \mathrm{P}<0.05,{ }^{* *} \mathrm{P}<0.01,{ }^{* * *} \mathrm{P}<0.001 . \mathrm{ns}$, no significance; $\mathrm{VC}$, vehicle control; RANTES, regulated upon activation, normal $\mathrm{T}$ cell expressed and presumably secreted; COX-2, cyclooxygenase-2.

tannins, terpenoids, saponins and phenolic compounds (57). Each bioactive agent may have a specific function in relation to the different aspects of the wound-healing process. For instance, saponins are able to augment the synthesis of pro-collagen from fibroblasts, whereas tannins and flavonoids have antiseptic and antibacterial properties, respectively $(32,58,59)$. Hence, these phytochemicals may regulate one or more aspect(s) of the wound-healing process and these components may be easily absorbed by the outer layers of the skin (60). Owing to their anti-inflammatory, wound healing and analgesic properties, herbal products have emerged as an important therapeutic option for the treatment of numerous diseases of different severity. In addition to their biological activity, they also potentially provide important leads for the design of novel synthetic compounds $(31,46)$. A previous study by our group reported that AnoSpray exhibits wound-healing effects on perineal wounds without causing any side effects (37). However, the mechanism underlying this healing activity on perineal wounds was not identified in that study. The present study demonstrated that AnoSpray suppresses the migration of fibroblasts and macrophages, as well as by reducing the expression levels of the proinflammatory cytokines RANTES and VEGF. COX-2 fulfills a crucial role in mitigating acute pain by regulating prostaglandin production and COX-2 inhibitors have been widely used for treating pathological pain associated with numerous diseases $(61,62)$. In the present study, it was determined that AnoSpray reduced the expression of COX-2 in fibroblasts and macrophages. Of note, the present clinical data also indicated that the expression levels of COX-2 and RANTES were downregulated in AnoSpray-treated hemorrhoids. In addition, AnoSpray 

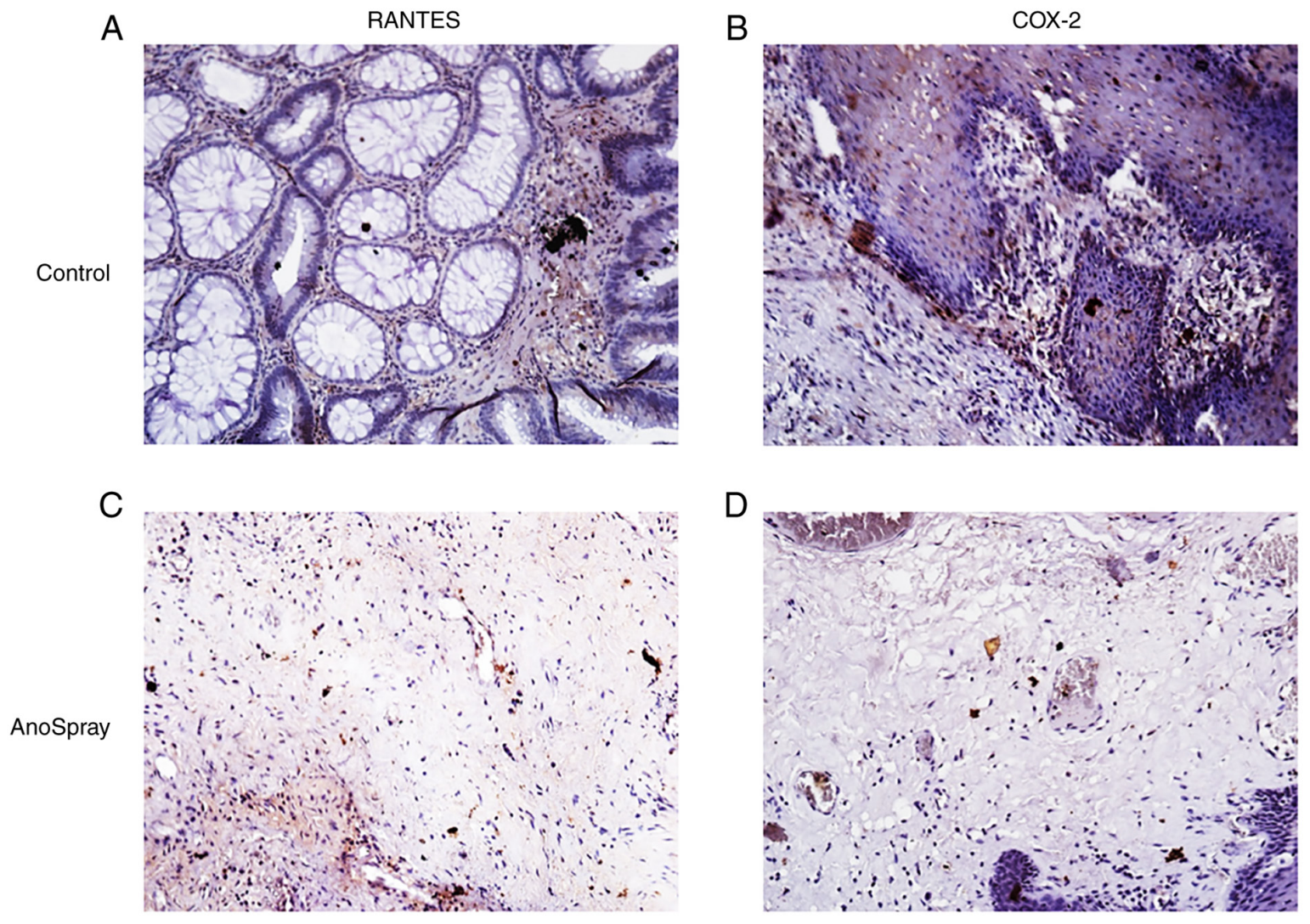

Hemorrhoids

Figure 4. Expression of RANTES and COX-2 in clinical specimens of hemorrhoids. Expression of RANTES and COX-2 in hemorrhoidal disease tissues was analyzed using immunohistochemistry $(\mathrm{n}=10)$. Among the 10 hemorrhoidal specimens, 5 patients were untreated, whereas 5 more patients were treated with AnoSpray ${ }^{\circledR}$. (A and B) Expression of (A)RANTES and (B) Cox-2 in hemorrhoids. (C andD) Expression of (C) RANTES and (D) COX-2 in AnoSpray ${ }^{\circledR}$-treated hemorrhoids (magnification, x200). RANTES, regulated upon activation, normal T cell expressed and presumably secreted; COX-2, cyclooxygenase-2.

did not have any apparent effects on the viability of macrophages and fibroblasts. The major limitation of the present study was that the expression of RANTES and COX-2 in anorectal disease tissues was not compared with that in control anorectal tissues. AnoSpray is a polyherbal formulation comprising B. aristata, $S$. racemosa, B. ceiba, S. indicum, G. indica, C. camphora and $M$. piperita extracts. B. aristata and $S$. racemosa that was previously reported to exhibit antioxidant, anti-inflammatory, antiangiogenic and wound-healing properties $(63,64)$. Another study also reported that normal and delayed wound healing was enhanced by sesamol derived from $S$. indicum in albino rats (65). As a traditional medicine, $B$. ceiba has been used in the healing of wounds, exhibiting anti-inflammatory, antioxidant and antidiabetic activities (66). An earlier study indicated that Kokum butter, which is derived from $G$. indica and has traditionally been employed for the treatment of wounds and fissures in hands, restores the elasticity of the skin, acting as a moisturizer (67). The leaves of $C$. camphora have been employed as a therapeutic option for the treatment of various skin disorders, anti-inflammatory disorders and antimicrobial diseases, in view of its antioxidant activities (68). Furthermore, an extract of $C$. camphora leaves promoted wound-healing activity in rats (68). Modarresi et al (69) demonstrated that the topical application of essential oil derived from $M$. piperita augmented wound healing in an infected mouse model. It is hypothetically possible that the polyherbal formulation of AnoSpray acts at different phases of inflammation, wherein pain is induced or where healing has been initiated, thereby leading to an improvement in patients' lives. The present study highlighted that AnoSpray is both safe to use and therapeutically effective in treating anal fissures, bleeding hemorrhoids and perineal wounds.

In conclusion, the present study suggested that AnoSpray does not exhibit any cytotoxic effects on macrophages or fibroblasts, thereby demonstrating that it is safe to use. Furthermore, its administration leads to a significant attenuation of the migration of these cells and also suppresses the expression of proinflammatory mediators and COX-2, both in vitro and in clinical specimens. The results of the present study highlighted the potential implications of AnoSpray as a means of therapy for clinically controlling bleeding hemorrhoids and in the treatment of anal fissures and perineal wounds.

\section{Acknowledgements}

The authors would like to thank Dr Snehal Porwal, Founder and Director, Healing Hands and Herbs Pvt. Ltd. (Pune, India) for valuable support.

\section{Funding}

No funding was received. 


\section{Availability of data and materials}

The datasets used and/or analyzed during the current study are available from the corresponding author on reasonable request.

\section{Authors' contributions}

The study was conceived and designed by AP, GCK, RB and GB. Herbal materials were prepared and supplied by AP, GB and RB. Experiments were performed by RB. The data were analysed and the manuscript was written and edited by RB, AP, GB and GCK. RB, AP, GB and GCK confirmed the authenticity of the data. All authors have read and approved the final manuscript.

\section{Ethics approval and consent to participate}

This study was approved by the Institutional Ethics Committee of Healing Hands Clinic (Pune, India). Human hemorrhoid specimens were collected from Healing Hands Clinic (Pune, India) with informed consent.

\section{Patient consent for publication}

Not applicable.

\section{Competing interests}

GB and RB are employees of Healing Hands \& Herbs Pvt. Ltd., who provided the pharamceutical product used in this study.

\section{References}

1. Foxx-Orenstein AE, Umar SB and Crowell MD: Common anorectal disorders. Gastroenterol Hepatol (NY) 10: 294-301, 2014.

2. Hollingshead JR and Phillips RK: Haemorrhoids: Modern diagnosis and treatment. Postgrad Med J 92: 4-8, 2016.

3. Mott T, Latimer K and Edwards C: Hemorrhoids: Diagnosis and treatment options. Am Fam Physician 97: 172-179, 2018.

4. Guindic LC: Treatment of uncomplicated hemorrhoids with a Hemor-Rite ${ }^{\circledR}$ cryotherapy device: A randomized, prospective, comparative study. J Pain Res 7: 57-63, 2014.

5. Lorenzo-Rivero S: Hemorrhoids: Diagnosis and current management. Am Surg 75: 635-642, 2009.

6. Sun Z and Migaly J: Review of hemorrhoid disease: Presentation and management. Clin Colon Rectal Surg 29: 22-29, 2016.

7. Chong PS and Bartolo DC: Hemorrhoids and fissure in ano. Gastroenterol Clin North Am 37: 627-644, ix, 2008.

8. Jacobs D: Clinical practice. Hemorrhoids. N Engl J Med 371: 944-951, 2014.

9. Riss S, Weiser FA, Schwameis K, Riss T, Mittlböck M, Steiner G and Stift A: The prevalence of hemorrhoids in adults. Int J Colorectal Dis 27: 215-220, 2012.

10. Lohsiriwat V: Hemorrhoids: From basic pathophysiology to clinical management. World J Gastroenterol 18: 2009-2017, 2012.

11. Morgado PJ, Suárez JA, Gómez LG and Morgado PJ Jr: Histoclinical basis for a new classification of hemorrhoidal disease. Dis Colon Rectum 31: 474-480, 1988.

12. Han W, Wang ZJ, Zhao B, Yang XQ, Wang D, Wang JP, Tang XY, Zhao F and Hung YT: Pathologic change of elastic fibers with difference of microvessel density and expression of angiogenesis-related proteins in internal hemorrhoid tissues. Zhonghua Wei Chang Wai Ke Za Zhi 8: 56-59, 2005 (In Chinese).

13. Yoon SO, Park SJ, Yun CH and Chung AS: Roles of matrix metalloproteinases in tumor metastasis and angiogenesis. J Biochem Mol Biol 36: 128-137, 2003.
14. Zagriadskiı EA, Bogomazov AM and Golovko EB: Conservative treatment of hemorrhoids: Results of an observational multicenter study. Adv Ther 35: 1979-1992, 2018.

15. Cerato MM, Cerato NL, Passos P, Treigue A and Damin DC: Surgical treatment of hemorrhoids: A critical appraisal of the current options. Arq Bras Cir Dig 27: 66-70, 2014.

16. Santos GD, Coutinho CP, Meyer MM, Sampaio DV and Cruz GM: Surgical complications in 2,840 cases of hemorrhoidectomy by Milligan-Morgan, Ferguson and combined techniques. J Coloproctol (Rio J) 32: 271-290, 2012.

17. Higuero T: Update on the management of anal fissure. J Visc Surg 152 (Suppl 2): S37-S43, 2015.

18. Villalba H, Villalba S and Abbas MA: Anal fissure: A common cause of anal pain. Perm J 11: 62-65, 2007.

19. Notaras MJ: Anal fissure and stenosis. Surg Clin North Am 68: $1427-1440,1988$

20. Tranqui P, Trottier DC, Victor C and Freeman JB: Nonsurgical treatment of chronic anal fissure: Nitroglycerin and dilatation versus nifedipine and botulinum toxin. Can J Surg 49: 41-45, 2006.

21. Nottingham JM and Rentea RM: Anal Fistulotomy (Seton Placement). In: StatPearls. StatPearls Publishing, Treasure Island, FL, 2020.

22. Gardner IH, Siddharthan RV and Tsikitis VL: Benign anorectal disease: Hemorrhoids, fissures, and fistulas. Ann Gastroenterol 33: 9-18, 2020.

23. Sharma RK and Parashar A: The management of perineal wounds. Indian J Plast Surg 4: 352-363, 2012.

24. Whiteford MH: Perianal abscess/fistula disease. Clin Colon Rectal Surg 20: 102-109, 2007.

25. Bullard KM, Trudel JL, Baxter NN and Rothenberger DA: Primary perineal wound closure after preoperative radiotherapy and abdominoperineal resection has a high incidence of wound failure. Dis Colon Rectum 48: 438-443, 2005.

26. Musters GD, Sloothaak DA, Roodbeen S, van Geloven AA Bemelman WA and Tanis PJ: Perineal wound healing after abdominoperineal resection for rectal cancer: A two-centre experience in the era of intensified oncological treatment. Int J Colorectal Dis 29: 1151-1157, 2014.

27. Althumairi AA, Canner JK, Gearhart SL, Safar B, Sacks J and Efron JE: Predictors of perineal wound complications and prolonged time to perineal wound healing after abdominoperineal resection. World J Surg 40: 1755-1762, 2016.

28. Christian CK, Kwaan MR, Betensky RA, Breen EM,Zinner MJ and Bleday R: Risk factors for perineal wound complications following abdominoperineal resection. Dis Colon Rectum 48: 43-48, 2005.

29. Artioukh DY, Smith RA and Gokul K: Risk factors for impaired healing of the perineal wound after abdominoperineal resection of rectum for carcinoma. Colorectal Dis 9: 362-367, 2007.

30. Chang CC, Lan YT, Jiang JK, Chang SC, Yang SH, Lin CC, Lin HH, Wang HS, Chen WS, Lin TC and Lin JK: Risk factors for delayed perineal wound healing and its impact on prolonged hospital stay after abdominoperineal resection. World J Surg Oncol 17: 226, 2019.

31. Atanasov AG, Waltenberger B, Pferschy-Wenzig EM, Linder T, Wawrosch C, Uhrin P, Temml V, Wang L, Schwaiger S, Heiss EH, et al: Discovery and resupply of pharmacologically active plant-derived natural products: A review. Biotechnol Adv 33: 1582-1614, 2015.

32. Ibrahim N', Wong SK, Mohamed IN, Mohamed N, Chin KY, Ima-Nirwana S and Shuid AN: Wound healing properties of selected natural products. Int J Environ Res Public Health 15: 2360, 2018.

33. Santana FP, Pinheiro NM, Mernak MI, Righetti RF, Martins MA, Lago JH, Lopes FD, Tibério IF and Prado CM: Evidences of herbal medicine-derived natural products effects in inflammatory lung diseases. Mediators Inflamm 2016: 2348968, 2016.

34. Llorián-Salvador M and González-Rodríguez S: Painful understanding of VEGF. Front Pharmacol 9: 1267, 2018.

35. Sobolewski C, Cerella C, Dicato M, Ghibelli L and Diederich M: The role of cyclooxygenase-2 in cell proliferation and cell death in human malignancies. Int J Cell Biol 2010: 215158, 2010.

36. Cragg GM and Newman DJ: Natural products: A continuing source of novel drug leads. Biochim Biophys Acta 1830: 3670-3695, 2013.

37. Porwal A, Gandhi P and Kulkarni D: An open label, randomized, comparative, parallel group, single center study to evaluate safety and efficacy of Ano spray in a comparison with betadine solution application in acute perineum wounds. Ayushdhara 4: 1409-1412, 2017.

38. Kumar D, Haldar S, Gorain M, Kumar S, Mulani FA, Yadav AS, Miele L, Thulasiram HV and Kundu GC: Epoxyazadiradione suppresses breast tumor growth through mitochondrial depolarization and caspase-dependent apoptosis by targeting PI3K/Akt pathway. BMC Cancer 18: 52, 2018. 
39. Chakraborty G, Jain S and Kundu GC: Osteopontin promotes vascular endothelial growth factor-dependent breast tumor growth and angiogenesis via autocrine and paracrine mechanisms. Cancer Res 68: 152-161, 2008

40. Kumar D, Kumar S, Gorain M, Tomar D, Patil HS, Radharani NN, Kumar TV, Patil TV, Thulasiram HV and Kundu GC: Notch1-MAPK signaling axis regulates $\mathrm{CD}_{133^{+}}$cancer stem cell-mediated melanoma growth and angiogenesis. J Invest Dermatol 136: 2462-2474, 2016

41. Landén NX, Li D and Ståhle M: Transition from inflammation to proliferation: A critical step during wound healing. Cell Mol Life Sci 73: 3861-3885, 2016

42. Guo S and Dipietro LA: Factors affecting wound healing. J Dent Res 89: 219-229, 2010.

43. Chen S and Yu Q: A new theory on the cause of anal fissure-impaction theory. J Coloproctol (Rio J) 40: 321-325, 2020.

44. Segre D, Dal Corso HM, Landra $M$ and Giuffrida MC: Management of the unhealed perineal wound. In: Inflammatory bowel disease and familial adenomatous polyposis. Springer, Milano, pp463-472, 2006.

45. Bertone AL: Principles of wound healing. Vet Clin North Am Equine Pract 5: 449-463, 1989.

46. Derakhshan AR: Natural treatments for fissure in ano used by traditional persian scholars, Razi (Rhazes) and Ibn Sina (Avicenna). J Evid Based Complementary Altern Med 22: 324-333, 2017

47. Dey YN, Wanjari MM, Kumar D, Lomash V and Jadhav AD: Curative effect of Amorphophallus paeoniifolius tuber on experimental hemorrhoids in rats. J Ethnopharmacol 192: 183-191, 2016.

48. Azeemuddin M, Viswanatha GL, Rafiq M, Thippeswamy AH, Baig MR, Kavya KJ, Patki PS and Shyam R: An improved experimental model of hemorrhoids in rats: Evaluation of antihemorrhoidal activity of an herbal formulation. ISRN Pharmacol 2014: 530931, 2014

49. Wojdasiewicz P, Poniatowski ŁA and Szukiewicz D: The role of inflammatory and anti-inflammatory cytokines in the pathogenesis of osteoarthritis. Mediators Inflamm 2014: 561459, 2014.

50. Sprague AH and Khalil RA: Inflammatory cytokines in vascular dysfunction and vascular disease. Biochem Pharmacol 78 : 539-552, 2009

51. Fitzgerald SM, Lee SA, Hall HK, Chi DS and Krishnaswamy G: Human lung fibroblasts express interleukin-6 in response to signaling after mast cell contact. Am J Respir Cell Mol Biol 30 $585-593,2004$

52. Arango Duque G and Descoteaux A: Macrophage cytokines: Involvement in immunity and infectious diseases. Front Immunol 5: 491, 2014

53. Lohsiriwat V: Treatment of hemorrhoids: A coloproctologist's view. World J Gastroenterol 21: 9245-9252, 2015.

54. Mounsey AL, Halladay J and Sadiq TS: Hemorrhoids. Am Fam Physician 84: 204-210, 2011

55. Bhardwaj R and Parker MC: Modern perspectives in the treatment of chronic anal fissures. Ann R Coll Surg Engl 89: 472-478, 2007.
56. Dias DA, Urban S and Roessner U: A historical overview of natural products in drug discovery. Metabolites 2: 303-336, 2012.

57. Thakur R, Jain N, Pathak R and Sandhu SS: Practices in wound healing studies of plants. Evid Based Complement Alternat Med 2011: 438056, 2011.

58. Chandel RS and Rastogi RP: Triterpenoid saponins and sapogenins: 1973-1978. Phytochemistry 19: 1889-1908, 1980.

59. Harbone JB: Phytochemical methods: A guide to modern techniques of plants analysis. Fakenham Press Limited: New York, NY, USA, 1973.

60. Tsala DE, Amadou D and Habtemariam S: Natural wound healing and bioactive natural products. Phytopharmacology 4: 532-560, 2013

61. Ricciotti E and FitzGerald GA: Prostaglandins and inflammation. Arterioscler Thromb Vasc Biol 31: 986-1000, 2011.

62. Merecz-Sadowska A, Sitarek P, Śliwiński T and Zajdel R: Anti-inflammatory activity of extracts and pure compounds derived from plants via modulation of signaling pathways, especially PI3K/AKT in macrophages. Int J Mol Sci 21: 9605, 2020.

63. Potdar D, Hirwani RR and Dhulap S: Phyto-chemical and pharmacological applications of Berberis aristata. Fitoterapia 83: 817-830, 2012.

64. Acharya N, Acharya S, Shah U, Shah R and Hingorani L: A comprehensive analysis on Symplocos racemosa Roxb.: Traditional uses, botany, phytochemistry and pharmacologica activities. J Ethnopharmacol 181: 236-251, 2016.

65. Shenoy RR, Sudheendra AT, Nayak PG, Paul P, Kutty NG and Rao CM: Normal and delayed wound healing is improved by sesamol, an active constituent of Sesamum indicum (L.) in albino rats. J Ethnopharmacol 133: 608-612, 2011.

66. Rameshwar V, Kishor D, Tushar G, Siddharth G and Sudarshan G: A pharmacognostic and pharmacological overview on Bombax ceiba. Sch Acad J Pharm 3: 100-107, 2014.

67. Ananthakrishnan R and Rameshkumar KB: Phytochemicals and bioactivities of Garcinia indica (thouars) choisy-a review. Divers Garcinia Species West Ghats: Phytochem Perspect 142: 151-161, 2016.

68. Sen PK and Garg S: Wound repair and regenerating effect of ethyl acetate soluble fraction of ethanolic extract of Cinnamomum camphora leaves in wistar albino rats. J Drug Deliv Ther 9: 1173-1176, 2019.

69. Modarresi M, Farahpour MR and Baradaran B: Topical application of Mentha piperita essential oil accelerates wound healing in infected mice model. Inflammopharmacology 27: 531-537, 2019. International (CC BY-NC-ND 4.0) License. 